\title{
Development of learning package for enhancing reading and writing achievement in Thai for communication course for undergraduate students
}

\author{
Sasipong Srisawat \\ Udon thani Rajabhat University, Thailand
}

\begin{tabular}{l}
\hline \hline Article Info \\
\hline Article history: \\
Received June 12, 2021 \\
Revised September 1, 2021 \\
Accepted September 9, 2021
\end{tabular}

Keywords:

learning package

reading and writing

Thai for communication

\begin{abstract}
The objectives of this study were 1) to develop learning packages to improve reading and writing performance in Thai for undergraduate students' communication course to meet the $80 / 80$ criteria, 2) to compare the learning outcomes of the learning packages using pre- and post-tests, and 3) to investigate students' attitudes toward the learning packages. The research instrument used in the current study was the learning package. The sample group included 50 students enrolled in the Thai for Communication course. The statistics used in the data analysis were percentage, mean, standard deviation, and t-test. The results of the investigation were as follows: 1) the learning package was used to promote reading and writing performance in Thai language communication course, the quality was of high and efficiency according to the standard criteria, 2) the Thai language reading and writing performance, after learning with the learning package, was significantly higher than before learning at the .05 level, and 3) the students' attitude toward learning with the learning package was at the extremely high level.
\end{abstract}

This is an open access article under the $\underline{C C B Y-S A}$ license.

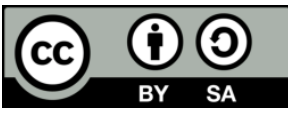

\section{Corresponding Author}

Sasipong Srisawat

Udon thani Rajabhat University

Thailand

E-mail:penthai_88@windowslive.com

\section{INTRODUCTION}

Thai is the official language of Thailand and the native language of Thai people. It is regarded as the cultural treasure, also served as a means of communicative spoken language for people in the country. It helped to create understanding and a feeling of solidarity as well. The Thai language literacy of Thai people will lead to normal daily living, including doing business, causing good interactions to one other. It can be seen that education, exchanging ideas, expressing concepts, arts, and sciences, all required the use of Thai language. Therefore, teaching Thai language is crucial in developing people in the nation to use the Thai language effectively for the development of their own knowledge and abilities to inherit the language heritage which is national culture and have a good attitude towards Thai language and be able to communicate effectively.

Reading plays a fundamental role in learning new vocabulary. Reading a lot builds word memory in the human brain. Skilled readers will have the ability to convey stories well linguistically because they have many words to choose from, leading to rhetorical expression in communication. (Aksornkan, 2016; Kaewnunual \& Chalongdet , 2018; Kramjantuek, 2018). Writing is an advanced language skill formed by integrating knowledge and ideas through various experiences. Writing is a more complex language skill than any other skill because 
writing a story requires the art of word choice, as well as arranging ideas into written language that is readable, understandable, clear, and graceful )Chiowohan et.al., 2014; Ronnayut \& Sornjitti, 2019 (.

Reading and writing are interrelated. It has been shown that readers can take the knowledge gained from reading to improve their writing skills. Reading skill is, therefore, essential as it is a tool to acquire knowledge and writing strategies to develop writing. Reading and writing skills are essential skills as tools to develop people in the society to be desirable qualities as required in today's world. Because reading can develop human as a tool to search, analyze, organize and process a variety of knowledge and information, moreover writing presents information that is synthesized and presented in an artistic way. Both reading and writing are important communication skills and are inextricably linked. It is a complementary process because reading gained information that become knowledge, study and understand the writing styles of what they have read. While writing is the product of data collection, analysis and imitation obtained from reading.

The test results of reading and writing skills of learners enrolled in Thai language for communication course, Office of General Education, Udon Thani Rajabhat University, showed that students have problems in reading and writing, such as the ability to read for comprehension, analyze what they read, write logically, and hit the point they want to express. Incorrect spelling is also a problem. Therefore, it is very important to find a way to solve these problems. A review of the work found that the use of learning package is one way to achieve teaching and learning objectives. The use of learning package is one of the most effective innovations. It enables students to learn quickly and achieve the set goals )Boonsathirakul, et al, 2016; Sooksabay, 2018) From the foregoing, the researcher's interest is to develop a learning package for Thai language communication courses to promote Thai language reading and writing performance for undergraduate students, motivate them to learn and acquire knowledge from the classroom, and improve students' reading and writing performance. In addition, such research will help those involved in producing graduates and developing their communication skills.

As a result, graduates are of sufficient quality to develop the country in a desirable direction according to the National Strategy (2018-2037) which aims to develop people of all ages qualitatively. It also helps to increase the quality of graduates which is an important factor affecting the overall quality of education in the country. This research aims to develop a learning package to improve reading and writing performance in Thai for an undergraduate communication course to meet the $80 / 80$ criteria, and to compare the learning outcomes of the learning packages using pre- and post-tests, and 3) to investigate students' attitudes toward the learning packages. The research tool used in the current study was a learning package.

\section{RESEARCH METHOD}

\section{Population and sample}

They are undergraduate students at Udon Thani Rajabhat University, who enrolled in the course Thai for communication in the first semester of the academic year 2019, number of populations was 300 students. The sample group is undergraduate students at Udon Thani Rajabhat University who enrolled in the Thai for communication course in the second semester of the 2019 academic year, 50 students of sample were obtained from cluster random sampling method.

\section{Variables}

1. Independent Variable includes learning package to promote reading and writing performance in Thai language for communication course for undergraduate students,

2. The dependent variable is learning outcomes from using learning package to promote reading and writing performance in Thai language for communication course for undergraduate students.

\section{Data collection}

Step 1: Development of learning package and lesson plan for enhancing reading and writing achievement in Thai for Communication Course for undergraduate students. The researcher studied and reviewed the literature on developing a learning package and guidelines for creating lesson plan. Development of 6 learning package and 6 lesson plans for teachers. Five experts checked up the lesson plans to examine the Index of Item Objective Congruence (IOC) between the questions and the objectives of the study. Furthermore, to look at the quality of the learning package and provide comments to improve the learning package. Improving the learning package and lesson plans as per the recommendations reviewed by the experts and revised accordingly. The implemented learning package and lesson plans were tried out with non-sample students to study the effectiveness of the learning package.

The test has the accuracy value from the consistency between experts (Index of Item - Objective Congruence) between 0.60-1.00, can be used for a total of 83 items out of 100 items, and then used to find the difficulty $(\mathrm{P})$ with a value of $0.2-0.8$ and the value $(\mathrm{R})$ with a value of 0.2 or higher, then determine the confidence of the test and select the remaining 60 items as appropriate and consistent with the objectives. The test was a multiple-choice test with 4 options, 60 items, 60 items, had a consistency (IOC) between 0.67-1.00, a difficulty (P) between 0.20-0.79, a discriminatory power (R) between $0.37-0.93$ and has a confidence (reliability) of 0.82 .

Application of the learning package to the non-sample students obtained through Cluster Random Sampling i.e., 3 students in the second semester of the academic year 2017 to check the efficiency of the one-to-one 
experiment. The efficiency value of lesson plan E1/E2 $=81.02 / 80.56$. For the second semester of academic year 2018 , to check the efficiency (Small Group Tryout) with a small group of 10 students. The results show that the efficiency of lesson plan E1/E2 $=82.14 / 81.83$. And for the second semester of academic year 2019, the efficiency (Field Tryout) of 30 students had an efficiency value of lesson plan E1/E2 $=82.86 / 81.72$. It indicated that the lesson plan prepared by the researcher was effective according to the $80 / 80$ benchmark.

Step 2 : Using learning package and lesson plan for enhancing reading and writing achievement in Thai for communication course for undergraduate students with the sample group who were in academic year 2/2019. the number of students in the classroom were 50 students and obtained by cluster random sampling.

Step 3:Assessing learners' opinions about the literacy learning package; Thai language for communication course for undergraduate students.

\section{Data Analysis}

The data analysis and statistics used in the research are as follows:

1. information from the documents related to the creation of the learning package and the guidelines for creating the learning management plan using content analysis.

2. finding the quality of the tools: 1) Finding the consistency index between the questions and the learning objectives in the test (IOC), 2) Assessing the degree of adequacy of the learning management model using the 5point Likert rating, 3) to determine the difficulty of the test $(\mathrm{p}), 4)$ to determine the dissimilarity of the test $(\mathrm{r}), 5$ ) to determine the confidence of the test (Kuder-Richardson) using the KR -20.

3. to examine the effectiveness of the learning management plan according to the $80 / 80$ criteria (Brahmawong, 2013).

4. The data and statistics were analyzed using descriptive statistics to draw conclusions about the important characteristics of the data. The statistical values used were percentage, mean and Standard Deviation. The differences between pre and post test scores were analyzed using Dependent Samples t-test.

5. analyze students' opinions about learning by using Likert's (1967) 5-level rating questionnares.

\section{RESULT AND DISCUSSION}

Development of learning package for enhancing reading and writing achievement in Thai for Communication Course for undergraduate students, it can be summarized the objectives as follows:

The results of the development of learning package for enhancing reading and writing achievement in Thai for communication course for undergraduate students (Table 1).

Table 1 The quality assessment of learning package

\begin{tabular}{|c|c|c|c|c|c|c|c|c|}
\hline \multirow{2}{*}{ Items } & \multicolumn{5}{|c|}{ Experts' opinions } & \multirow[t]{2}{*}{$\overline{\mathrm{x}}$} & \multirow[t]{2}{*}{ S.D. } & \multirow[t]{2}{*}{ Quality } \\
\hline & 1 & 2 & 3 & 4 & 5 & & & \\
\hline 1. Objectives & 5.00 & 4.33 & 4.00 & 4.33 & 4.00 & 4.33 & 0.06 & Good \\
\hline 2. Contents & 5.00 & 4.20 & 4.40 & 4.60 & 4.00 & 4.44 & 0.04 & Good \\
\hline 3. Activities & 5.00 & 4.25 & 4.25 & 4.50 & 4.00 & 4.40 & 0.05 & Good \\
\hline 4. Book format & 4.33 & 4.33 & 4.33 & 4.33 & 4.00 & 4.27 & 0.06 & Good \\
\hline \multicolumn{6}{|c|}{ Totally } & 4.36 & 0.01 & Good \\
\hline
\end{tabular}

Table 1 showed the results of the data analysis to determine the quality of the learning package to promote the achievement of reading and writing in the Thai language for communication course. for undergraduate students from 5 experts, the quality of the learning package in all aspects was at a good level with a mean of 4.36 and a standard deviation of 0.01 . The researcher studied related documents and research involved to the topic along with conducting the study about the current reading and writing guidelines. Therefore, this learning package 's content was up-to-date both knowledge and illustrations. As a result, it become the high level of quality. The results were consistent with the concept of Utranan (1986) that developed learning package according to the 4-step process, namely the study of basic information; drafting a learning package, take the learning package for a quality assessment from experts, and evaluate and improve. theses process represented the implementation of an activity from start to finish. It is considered a systematic development process. Thiankhanithikun \& Wongdokmai )2015(, the quality from the experts Then improve and test with the sample. and consistent with research by Boonmahome et.al. (2019) Development of interactive online lessons on Learning Theory of Learning Psychology for Media Design The quality of lessons was assessed by experts. and then used to study the efficiency in the next step.

The results of the efficiency analysis of the learning package for promoting the achievement of reading and writing in Thai language for communication course for undergraduate students Th The results of the efficacy analysis of the learning package for promoting the achievement of reading and writing in Thai language for communication course for undergraduate students the results are shown in Table 2. 
Table 2 Efficiency of the learning package

\begin{tabular}{|c|l|c|c|}
\hline No. & \multicolumn{1}{|c|}{ Items } & $\mathrm{E}_{1}$ & $\mathrm{E}_{2}$ \\
\hline 1 & $21^{\text {st }}$ century communication & 80.17 & 81.39 \\
\hline 2 & Reading foe career in the present time & 82.06 \\
\hline 3 & Reading for writing & 82.61 \\
\hline 4 & Basic writing & 84.44 \\
\hline 5 & 4.0 Writing types in the 4.0 age & 86.50 & \\
\hline 6 & Creative writing on Public Media & 82.86 & 81.72 \\
\hline
\end{tabular}

From Table 2, it can be seen that the efficiency of learning package for undergraduate students In the nonsample group using the $80 / 80$ criterion, it was found that the process evaluation (E1) had an efficiency value of 82.86 and the outcome evaluation (E2) had an efficiency value of 81.72, which satisfies the stated criterion, 80/80, indicating that the effectiveness was appropriate and can be used in the classroom.

The learning package for enhancing reading and writing achievement in Thai for communication course for undergraduate students has an efficiency of 80/80 because the researcher has conducted the document research on the Thai language for communication course in Udon Thani Rajabhat University which consists of manuals, documents, textbooks, together with the study of principles of creating learning package and creating learning activities that are consistent with the content of the lesson as a guideline for creating learning kits and through validation and assessment of the quality of the learning package. The researcher-created learning package were assessed through quality assessments and testing for difficulty, classification power, and the confidence value of the whole test In addition, one to one tryout, small group try out, and learning set improvements were performed prior to field tryout. This corresponds to the practical application of knowledge in daily life. In line with the concept of Brahmawong (2013) mentioned. Media performance test or tutorial series It has to be quality checked and the effectiveness of the material or instruction set before it is put into practice.

This is consistent with the concept of Sikkhabandit (1985) said that the teaching set before being used in practice should be tested and modified to meet the standards first. to know how quality or deficiencies the instructional package is And the researcher should bring the teaching package to experiment with non-sample students to determine what should be improved. and then edited Then the teaching set was taken to experiment with the sample group. In line with the research of Harnkajornsuk (2019) has developed a math learning kit to promote the mental math of gifted students in primary school. and consistent with the research of Thipsuwan \& Yenbutra (2016) The researcher used the teaching package to test its effectiveness. and make improvements in the parts found during the teaching practice to make the tutorial as complete as possible before putting it into practice.

Comparison of learning success by using learning packages to promote reading and writing performance in Thai language for undergraduate communication course and pre and post learning, the results are shown in Table 3.

Table 3 Pretest and posttest scores

\begin{tabular}{|c|c|c|c|c|c|}
\hline Test & $\mathrm{N}$ & Total & $\overline{\mathrm{x}}$ & S.D. & $\mathrm{t}$ \\
\hline Pretest & 50 & 60 & 41.06 & 52.14 & \multirow{2}{*}{$22.47 *$} \\
\hline Posttest & 50 & 60 & 3.48 & 1.84 & \\
\hline
\end{tabular}

*Statistical significance level at .01 level

From table 3 the experimental results of using learning package for undergraduate students, found that learners had a statistically significant higher posttest performance score at the .01 level, which was higher than that of the pretest.

The learning achievement from using the learning package for enhancing reading and writing achievement in Thai for Communication Course after studying is higher than before. This is due to the learning package created by the researcher contains elements, sorting content from easy to difficult. Learners can gain knowledge from reading gradually. Developing learning to integrate knowledge from reading to writing in various formats that correspond to the state of human exposure in the present and the content illustrations of each lesson are clear, modern, suitable for the age of the learners. Students were interested in the content of the learning package and have good interaction with learning, resulting in learners having scores from the test after studying significantly higher than before at 0.01 .

This was consistent with the concept of Srisa-ard )2017( that the components of the teaching set must include a teacher manual Order card, task cards, media and quizzes. These elements will contribute to the development of teaching sets to be successful in learning management. The research of Phongpluem and 
Chamnankit (2014( indicated that development of a teaching package for teaching science process skills, teaching documents and a quiz at the end of the lesson resulting in higher test scores of the posttest than the pretest. And in line with the research of Chimpalee et.al. (2017) developed a series of teaching basic Chinese language by applying a collaborative learning process by creating learning content that is close to the learners to apply into a learning package. Each lesson was consistent and has a hierarchy of learning from easy to difficult. As a result, from using the teaching package, learners have higher achievement after learning than before.

The results of students' opinions on the learning package for enhancing reading and writing achievement in Thai for the communication course for undergraduate students as shown in Table 4.

Table 4 Students' opinions on the learning package

\begin{tabular}{|l|c|c|c|}
\hline \multicolumn{1}{|c|}{ Items } & \multicolumn{3}{c|}{ Levels } \\
\cline { 2 - 4 } & $\overline{\mathrm{x}}$ & $\mathrm{S} . \mathrm{D}$. & Interpretation \\
\hline 1. The handout is interesting with beautiful illustrations & 4.50 & 0.51 & Highest \\
\hline 2. The content is understandable & 4.46 & 0.50 & High \\
\hline 3. The directions for each lesson exercise was clear & 4.60 & 0.49 & Highest \\
\hline 4. the activities were ordering from east to difficulty & 4.46 & 0.50 & Highest \\
\hline 5. The timing for each lesson was suitable & 4.54 & 0.50 & Highest \\
\hline 6. The illustrations went along with the conversations & 4.56 & 0.50 & Highest \\
\hline 7. Each unit contained interesting learning activities & 4.82 & 0.39 & Highest \\
\hline 8. Self-study was included in the learning package & 4.52 & 0.50 & Highest \\
\hline 9. Learners are happy while learning & 4.24 & 0.43 & High \\
\hline $\begin{array}{l}\text { 10. The leaning package helped learners to acquire more } \\
\text { language skill }\end{array}$ & 4.48 & 0.50 & High \\
\hline
\end{tabular}

From Table 4, the results of examining learners' opinions on learning package for undergraduate students can be seen, it was overall at the highest level with 4.52 of mean and 0.04 of standard deviation. Looking at the individual items, the item that had the highest mean score was the attractiveness of the content of learning package.

The result of the study of learners' opinions towards the learning package for enhancing reading and writing achievement in Thai for communication course for undergraduate students was at a high level because the learning package in each lesson contained content that was consistent with their lifestyle. Present in communication of Thai society There is a beautiful book layout. The picture is clear and modern. There are activities in the lessons that are not too difficult and can be used to study on their own. As a result, the overview in each lesson is interesting. There is a clear explanation for doing exercises at the end of the lesson. Make learners happy in learning with such learning kits. In line with the concept of Pankhian (2006) mentioned that the development of learning kits requires content arrangements to suit learners. There should be a hierarchical arrangement of learning content. so that students have a systematic learning In line with the research of Milung, Srisanyong and Rattanampornsopon )2018 (developed a learning activity set to develop Analytical reading ability of Thai language learning subject groups By providing content in learning in order Students can study and research on their own. As a result, the students' opinions on the learning activities were at a high level.

\section{CONCLUSION}

From this research, encouraging students to engage in collaborative activities in small groups is an important part of getting them to learn and try challenging activities. Brainstorming takes place within the group. This leads to students showing more interest and learning strategies for reading and writing. The teacher is instrumental in planning learning that is appropriate and consistent for diverse learners. The teacher must understand adapting the content. The learning process is consistent with the learners' context and should encourage learners to learn independently. This learning pack is part of the courses in the School of General Education. Therefore, it is suitable for learners who have a basic knowledge of Thai language from senior high school or equivalent level. The learning package is a continuation of reading and writing from the regular curriculum and enables learners to develop their analytical, synthetic and creative applications. This leads to the development of communication in daily life.

\section{SUGGESTION}

1. The factors that influence the learning outcomes with the self-learning package should be investigated, such as internal factors, environmental factors, staff factors, etc.

2. A follow up study should be conducted after the entry into learning with the learning package. To see the persistence of knowledge about reading and writing and to document the problems and doubts of students in learning to use the information to improve the learning packages more effectively. 
3. The learning package should be developed to promote the performance of reading and writing in Thai language courses for communication for students in such a way that all learners can learn anywhere and anytime, such as learning through the website (website) or the development of various learning media such as e-book, elearning, including contemporary technology.

\section{REFERENCES}

Aksornkan, S. )2016(. Development of concept-oriented reading instruction and REAP strategy on Thai critical reading ability for undergraduate students of Suratthani Rajabhat University. Ratchaphruek Journal, 14)3(, 18-25.

Boonmahome, J., et al. )2019(. Development of interactive e-learning on learning theory in psychology of learning for media design. Journal for Social Sciences Research, 10)2(, 34-47.

Boonsathirakul, J., et al. )2016(. The development of the self-study package on psychology for teachers for college students. Suthiparithat Journal, 30(96), 1-13.

Brahmawong, C. (2013). Developmental testing of media and instructional package. Silpakorn Educational Research Journal, 5(1), 7-20.

Chimpalee, P., Bamroongcheep, U., \& Chaturanon, W. (2017). Development of instructional packages on beginning chinese by applying cooperative learning process for Prathomsuksa 5 students. Journal of Education, Naresuan University, 21)3(, 127-138.

Chiowohan, S., Mongkolthep, W., \& Soipora, P. )2014(. Appropriate teaching Thai methods according to the opinions of undergraduate students and lecturers at Rajamangala University of Technology Lanna. Journal of Education, Naresuan University, 16(3), 160-171.

Harnkajornsuk, S. (2019). A development of mathematics exploring package for enhancing mathematical minds of gifted students at the elementary level. Journal of Education Naresuan University, 21(1), 293-306.

Kaewnunual, W., \& Chalongdet, P. )2018(. An investigation of mistakes in Thai isage: A case study of Thai writing of first-year students at Princess of Naradhiwas University. Princess of Naradhiwas University Journal of Humanities and Social Sciences, 5(2), 1-11.

Kramjantuek, P. (2018). Creating a learning package to enhance ability of Thai usage for communication with reading and writing in the course Thai language and culture for being a teacher. Wiwitwannasan Journal, 2)1(, 97-101.

Milung, N., Srisanyong, S., \& Rattanampornsopon, U. )2018(. Result of using learning activity packages to develop analytical reading competency in thai subject area group for Mathayomsuksa 3 students apply the sq3r method. Journal of Education, Naresuan University, 20(4), 108-117.

Pankhian, A. (2006). The made of basic Thai language course for Red Karen war refugees. Chiang Mai: Chiang Mai University.

Phongpluem, R., \& Chamnankit, N. (2014). The development of the instructional packages on integrated science process skills of Matthayomsuksa 3 students. Journal of Graduate Studies in Northern Rajabhat Universities, 4(7), 11-24.

Sikkhabandit, S. (1985). Educational technology. Bangkok: Department of Technology Education King Mongkut, North Bangkok.

Srisa-ard, B. )2017(. Preliminary research. $10^{\text {th }}$ ed. Bangkok: Suwiriyasan.

Thiankhanithikun, T., \& Wongdokmai, R. )2015(. A development of learning package on food of three cultures in uttaradit province through community participation. Rajabhat Journal of Sciences, Humanities and Social Sciences, 16(2), 279-285.

Thipsuwan, O., \& Yenbutra, P. )2016(. Instructional package for language learning strategies on Thai heritageWorld Heritage for Foreign. KKU International Journal of Humanities and Social Sciences, 6(3), 96-1.

Ueatrirat, R., \& Sornjitti, N. )2019(. Analysis of Srinakharinwirot university students' errors in writing the thai language. Ganesha Journal, 15)1(, 87-100.

Utranan, S. (1986). Instructional management system. $5^{\text {th }}$ ed. Bangkok: Educational Administration. Faculty of Education, Chulalongkon University. 